\title{
Synthesis, characterization and antifungal activity of quaternary derivatives of chitosan on Aspergillus flavus
}

\author{
Rafael de Oliveira Pedro ${ }^{a}$, Mirelle Takaki ${ }^{a}$, Teresa Cristina Castilho Gorayeb ${ }^{\mathrm{b}}$, Vanildo Luiz Del Bianchi $^{\mathrm{b}}$, \\ João Cláudio Thomeo ${ }^{\mathrm{b}}$, Marcio José Tiera ${ }^{\mathrm{a}}$, Vera Aparecida de Oliveira Tiera ${ }^{\mathrm{a}, *}$

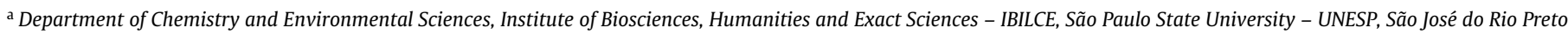 \\ São Paulo, Brazil

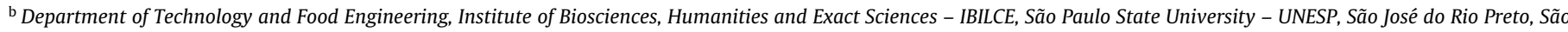 \\ Paulo, Brazil
}

\section{A R T I C L E I N F O}

\section{Article history:}

Received 29 February 2012

Received in revised form 16 June 2012

Accepted 23 June 2012

\section{Keywords:}

Chitosan

Derivatives

Aspergillus flavus

Antifungal activity

Mycotoxins

\begin{abstract}
A B S T R A C T
Two series of new chitosan derivatives were synthesized by reaction of deacetylated chitosan $(\mathrm{CH})$ with propyl (CH-Propyl) and pentyl ( $\mathrm{CH}$-Pentyl) trimethylammonium bromides to obtain derivatives with increasing degrees of substitution (DS). The derivatives were characterized by ${ }^{1} \mathrm{H}$ NMR and potentiometric titration techniques and their antifungal activities on the mycelial growth of Aspergillus flavus were investigated in vitro. The antifungal activities increase with DS and the more substituted derivatives of both series, $\mathrm{CH}$-Propyl and $\mathrm{CH}$-Pentyl, exhibited antifungal activities respectively three and six times higher than those obtained with commercial and deacetylated chitosan. The minimum inhibitory concentrations (MIC) were evaluated at 24,48 and $72 \mathrm{~h}$ by varying the polymer concentration from 0.5 to $16 \mathrm{~g} / \mathrm{L}$ and the results showed that the quaternary derivatives inhibited the fungus growth at polymer concentrations four times lower than that obtained with deacetylated chitosan $(\mathrm{CH})$. The chitosans modified with pentyltrimethylammonium bromide exhibited higher activity and results are discussed taking into account the degree of substitution (DS).
\end{abstract}

(c) 2012 Elsevier GmbH. All rights reserved.

\section{Introduction}

Chitosan is a polysaccharide usually obtained from deacetylation of chitin, which after cellulose is the second most abundant natural biopolymer found in nature. It may be extracted from various sources, particularly from exoskeletons of arthropods of crustaceans, fungi, insects, annelids, mollusks and coelenterata. The structures of chitin and chitosan correspond to those of poly[ $\beta(1 \rightarrow 4)$-2-acetamide-2-deoxy-D-glucopyranose] and poly[ $\beta(1 \rightarrow 4)$-2-amino-2-deoxy-D-glucopyranose], respectively (Ravi Kumar 2000). The homopolymer is a weak base with a $\mathrm{p} K_{\mathrm{a}}$ value of the $\mathrm{D}$-glucosamine residue of about $6.2-7.0$ and is therefore insoluble at neutral and alkaline $\mathrm{pH}$ values. In acidic mediums, the amine groups will be positively charged, conferring to the polysaccharide a high charge density. Due to its polycationic nature, chitosan, after being dissolved in aqueous acid solutions, can be easily molded and used as membranes, beads, microparticles and gels (Rinaudo 2006; Ravi Kumar 2000). Also, its functional properties such as biodegradability and low toxicity (Domard 2011; Kean and Thanou 2010) have driven the research

\footnotetext{
* Corresponding author. Tel.: +55 173221 2358; fax: +55 1732212356 .

E-mail address: verapoli@ibilce.unesp.br (V.A. de Oliveira Tiera).
}

and applications of chitosan to medicine (Rinaudo 2006; Shi et al. 2006; Jayakumar et al. 2010), foods additives and preservatives (Shahidi et al. 1999) as well as in the paper industry and for the treatment of industrial wastewater (Ngah and Teong 2011).

One of the most attractive features of chitosan is its antibacterial, antiviral and antifungal activity (Zhang et al. 2011; Jayakumar et al. 2011). Recently the utilization of chitosan as a food preservative or adjuvant in agriculture to protect or stimulate the defense of different crops has increased (Zhang et al. 2011; Jayakumar et al. 2011). It is well known that pesticide residues are toxic for humans and animals and many of them are not biodegradable, what can cause serious environmental problems such as contamination of the water and soil (Satpathy et al. 2011). Chitosan and its oligomers have emerged as a promising source for many applications since it can be used to produce biodegradable fungicides to regulate the growing of plants and to protect seeds (Alburquenque et al. 2010).

The antifungal activity of chitosan is believed to occur from the interaction between the cationic chain and the negatively charged residues of macromolecules exposed on the fungal cell surface, leading to leakage of intracellular electrolytes and other constituents (Muzzarelli et al. 2001). It is believed that chitosan may affect the morphogenisis of the cell wall interfering directly on the activity of enzymes responsible for the growing of the fungi (El Ghaouth et al. 1992). Recently Li et al., based on confocal laser 
scanning microscopy of fluorescein-labeled chitosans, showed that low molecular weight chitosans could enter into the hypha of Fulvia fulva, suggesting that the growth of $F$. fulva could be inhibited by chitosan from the inside of the cell (Li et al. 2011).

The fungus Aspergillus flavus is considered one of the most serious problems in the production and consumption of grains in the world as it is related to the production of mycotoxins, such as aflatoxins, which are produced as secondary metabolites by some strains of A. flavus (Binder et al. 2007; Zhang et al. 2009). Fajardo et al. (1994) reported that chitosan limited A. flavus growth and subsequent aflatoxin production by inducing susceptible tissues to produce more phenolic compounds. Recently, Zhang et al. prepared chitosan-based blend films using chitosan, soybean trypsin inhibitor extracts and glycerol solutions (Zhang et al., 2009). The authors showed that the germination and growth of $A$. flavus were strongly inhibited by films prepared from soybean trypsin inhibitor extract (STI)/wild soybean trypsin inhibitor extract (WTI) and glycerol (Gly) solutions (chitosan-STI/WTI-Gly), indicating that the films could be useful as potential bio-control packaging against A. flavus during the peanut's and other cereal's storage. The study of new biomolecules having antifungal activities has emerged as a new subject and the modification of the chitosan structure aiming to improve its activity is a promising way to achieve effective biofungicides (Kenawy et al. 2005; Másson et al. 2008) and bactericides (Xu et al. 2011).

The aim of the paper is to report a simple and reliable method to prepare chitosans derivatives with improved capabilities of inhibiting the growth of $A$. flavus. The synthesis, characterization and antifungal activity of chitosan derivatives against the fungus $A$. flavus are described. A series of chitosan derivatives was obtained by the reaction of the amino groups of chitosan with propyl and pentyltrimethyl ammonium bromides. The results of the antifungal activity of these derivatives were presented and discussed, taking into account the degree of substitution of the substituted derivatives.

\section{Materials and methods}

\subsection{Materials}

Chitosan (degree of deacetylation (DD) 85\%) was purchased from Polymar Co., Brazil, (3-bromopropyl) trimethylammonium bromide, (5-bromopentyl)trimethylammonium bromide, sodium hydroxide, sodium acetate, and acetic acid were purchased from Sigma Aldrich Chemical Co., Brazil. Spectra/pore membranes (Spectrum) were employed for dialysis. All solvents were of reagent grade and used as received. Water was deionized using a Gehaka water purification system.

\subsection{Instrumentation}

${ }^{1} \mathrm{H}$ NMR spectra were recorded on a Bruker ARX-500 $500 \mathrm{MHz}$ spectrometer. UV/Vis spectra were measured with a Cary $100 \mathrm{spec}-$ trophotometer equipped with a Peltier system. $\mathrm{pH}$ values of the solutions were determined using an Digimed $\mathrm{pH}$-meter.

\subsection{Preparation of the alkyltrimethylammonium-modified chitosans}

Chitosan was deacetylated as described earlier (Tiera et al. 2006). The resulting polymer was purified by dialysis against water for 3 days and isolated by lyophilization. Next, chitosans with varying amount of grafted alkyltrimethylammonium bromides were prepared in aqueous $\mathrm{NaOH}$ solutions and the procedure is described below (Fig. 1). The degree of substitution was varied by setting the initial molar ratio as described in Table 1 . A suspension of deacetylated chitosan $(1.5 \mathrm{~g}, 9.3 \mathrm{mmol})$ in aqueous $(20 \mathrm{~mL})$ was prepared and the $\mathrm{pH}$ was adjusted to 9.0 by adding $\mathrm{NaOH} 0.1 \mathrm{M}$ from an adapted funnel to a round-bottomed reaction flask equipped with a magnetic stirrer. Further (3-bromopropyl) trimethylammonium bromide $(1.0 \mathrm{~g})$ dissolved in water $(20 \mathrm{~mL})$ was added with stirring. Stirring was continued at $60^{\circ} \mathrm{C}$ for $72 \mathrm{~h}$ and the $\mathrm{pH}$ was continuously monitored during the reaction time. The mixture was then dialyzed (membrane of MWCO $12-14,000 \mathrm{~g} / \mathrm{mol}$ ) to remove the unreacted alquiltrimethylammonium bromide, first against water for 2 days, then against aqueous $\mathrm{NaOH}(0.05 \mathrm{M})$ for 1 day, and finally against water for 2 days. The product was isolated by lyophilization and characterized by ${ }^{1} \mathrm{H}$ NMR and potentiometry.

\subsection{Viscosity measurements}

Viscosity measurements were carried out in water thermostated bath with a capillary calibrated viscosimeter for dilution Cannon-Ubbelohde 9722M-50 (Cannon Instr. Co.) at pH 4.5 acetic acid $(0.3 \mathrm{M})$ /sodium acetate $(0.2 \mathrm{M})$ buffer. The viscosimeter was immersed in a thermostatic bath at $298.15 \pm 0.05^{\circ} \mathrm{C}$ and the samples were allowed to equilibrate for $10 \mathrm{~min}$ in the bath before measurements. Measurements at each concentration were repeated and the reproducibility was better than $\pm 0.01 \mathrm{~s}$. The results of the viscosity measurements were expressed as reduced viscosity values calculated from

$\eta=\frac{\left(t-t_{o}\right) / t_{o}}{c}$

where $t$ is the measured efflux time of the polymer solution, $t_{o}$ is the efflux time of the pure solvent, and $c$ is the polymer concentration $(\mathrm{g} / \mathrm{L})$. The mean viscosimetric molecular weight of chitosan and its derivatives were determined by using the Mark-Houwink equation, with constants $a=0.796, K=0.079 \mathrm{mLg}^{-1}$ (Roberts and Wang 1996).

\subsection{Pathogen and cultures}

The microorganism chosen to test the antifungal activity of chitosan and its derivatives was A. flavus. The strain was kindly provided by Brazilian Collection of Microorganisms from the Environment and Industry - CBMAI, Campinas - São Paulo, Brazil, and it was maintained on potato dextrose agar (PDA) (potato infusion from $200 \mathrm{~g} / \mathrm{L}, 20 \mathrm{~g} / \mathrm{L}$ dextrose, and $15 \mathrm{~g} / \mathrm{L}$ agar) in the dark at $25 \pm 2{ }^{\circ} \mathrm{C}$.

\subsection{Antifungal assays}

The antifungal activity of deacetylated and commercial chitosan was compared to those of the alkyltrimethylammonium derivatives modified with a degree of substitution varying from 0.5 to $65 \%$. The polymers solution were prepared at $\mathrm{pH} 5.5$ in acetic acid and added at concentrations of 0.0 (control plate) $0.1,0.5$ and $1.0 \mathrm{~g} / \mathrm{L}$ to the melted culture medium, which contained $10.0 \mathrm{~mL}$ of $10 \%$ potato dextrose broth and then transferred to Petri dishes. After solidification, the mixtures were inoculated with a $1 \mathrm{~mm}$ in diameter mycelium fungus A. flavus at the center of Petri dishes and these were incubated in an oven for 7 days at $25 \pm 2{ }^{\circ} \mathrm{C}$. Inhibition index of the fungus by the polymers was determined by the radial growth of the colony with a caliper on the 3rd, 5th and 7th days of cultivation, with the result of the 7th day used for comparative purposes.

The antifungal index was calculated as follows:

Antifungal index $(\%)=\frac{1-D_{a}}{D_{b}} \times 100$, 


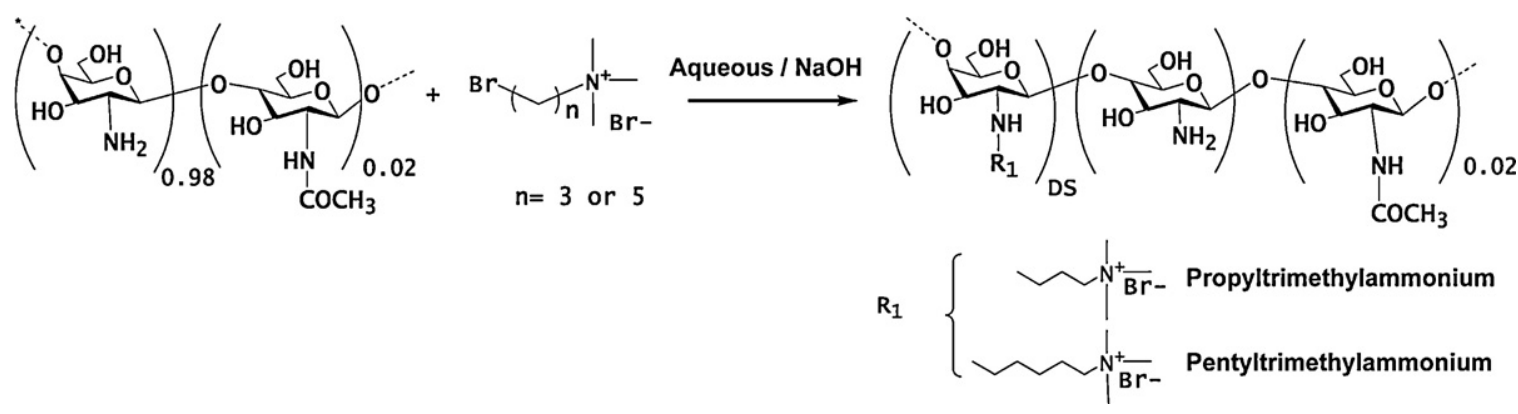

Fig. 1. Schematic representation of the synthesis of the quaternary derivatives of chitosan.

where $D_{a}$ is a diameter of the growth zone in the test plates and $D_{b}$ is growth zone in the control plate, according to Guo et al. (2006).

Each experiment was performed in quadruplicate, and the data were averaged. The student $T$-test and the Kruskal-Wallis test with Dunn's multiple comparison were used to evaluate the differences in antifungal index in antifungal tests. Results with $P<0.05$ were considered statistically significant.

\subsection{Minimum inhibitory concentrations}

The minimum inhibitory concentrations (MICs) were determined using the micro dilution assay in potato dextrose agar (PDA), following the standard method applied to filamentous fungi (CLSI 2008). The chitosan derivatives were dissolved in aqueous acetic acid at $\mathrm{pH} 5.5$ to obtain stock solutions of $16.0 \mathrm{~g} / \mathrm{L}$. These solutions were subsequently diluted to obtain decreasing polymer concentrations $(16.0,8.0,4.0,2.0,1.0,0.5,0.25 \mathrm{~g} / \mathrm{L})$. Thereafter $100 \mu \mathrm{L}$ of the polymer solutions was transferred on 96 -well plates and $2 \mu \mathrm{L}$ of the fungus suspension at a density of $10^{6}$ conidia/mL were inoculated at each well. The experiments were carried out in triplicate and the MICs were determined by visual inspection of the wells. The lowest concentration that gave complete growth inhibition in all three replicates was recorded as the minimum inhibitory concentration (MIC) after 24, 48 and $72 \mathrm{~h}$.

\section{Results and discussion}

\subsection{Preparation of the antifungal derivatives}

To achieve the functionalization of chitosan with quaternary amino groups, we used nucleophilic substitution of the $\mathrm{C}-2$ amine groups, thus leaving intact all the hydroxyl groups which play an important part in the biological activity of chitosan derivatives (Fig. 1). The synthetic strategy was successively carried out by using the alquiltrimethylammonium bromides. The transformation was carried out starting from a deacetylated chitosan, obtained via deacetylation of a commercial chitosan sample with a nominal degree of deacetylation (DD) of $85 \%$, following a previously described procedure (Tiera et al. 2006). The deacetylation was carried out under continuous bubbling of nitrogen in order to prevent degradation of the polymer. The degree of deacetylation, expressed in $-\mathrm{NH}_{2} \mathrm{~mol} \%$, determined from the ${ }^{1} \mathrm{H}$ NMR spectra of the starting material and the deacetylated sample, were 86.1 and $98.7 \mathrm{~mol} \%$, respectively. These values were obtained from the areas of the doublet at $5.5 \mathrm{ppm}$, due to the resonance of the anomeric proton (H1) and of the singlet at $2.7 \mathrm{ppm}$ attributed to the acetamido methyl protons (Fig. 2a). Potentiometric titration conducted on a solution of $\mathrm{CH}$ confirmed that the deacetylation occurred with high efficiency, yielding a DD value of 98.5 .

The degree of substitution was varied by setting the initial molar ratio of $\mathrm{N}$-alkyltrimethylammonium to glucosamine units to values ranging from 1.2 to 8.0. The ${ }^{1} \mathrm{H}$ NMR spectra of the chitosan derivative obtained from reaction with (3-bromopropyl) trimethylammonium bromide exhibited a singlet at $3.67 \mathrm{ppm}$, which was attributed to the resonance of the trimethylammonium protons of the $\mathrm{N}$-alkyltrimethylammonium moiety and also exhibited a signal at $\delta 2.81 \mathrm{ppm}$ corresponding to the resonance of the methylene protons $\mathrm{CH}_{2} \boldsymbol{C H}_{2} \mathrm{CH}_{2} \mathrm{~N}^{+}\left(\mathrm{CH}_{3}\right)_{3}$ (Fig. 2a). The attachment of alkyltrimethylammonium groups to the chitosan framework brings further changes to the ${ }^{1} \mathrm{H}$ NMR spectrum of chitosan, most notably in the resonances of the protons in close proximity to the substitution site: the anomeric proton $\mathrm{H}-1$ and the proton $\mathrm{H}-2$ linked to the $\mathrm{C} 2$ of the glucosamine unit. The anomeric proton signal undergoes a downfield shift, from $\delta 5.40 \mathrm{ppm}$ to $\delta 5.56 \mathrm{ppm}$, while the peak at $\delta 3.67 \mathrm{ppm}$ shifts to $3.85 \mathrm{ppm}$. The same pattern was also observed in the ${ }^{1} \mathrm{H}$ NMR spectra of the pentyltrimethylammonium derivatives, however the pentyltrimethylammonium bromide exhibited a triplet from 2.00 to $2.50 \mathrm{ppm}$ attributed to the methylene protons from pentyl hydrocarbon chain. Similar deshielding of $\mathrm{H}-1$ and $\mathrm{H}-2$ upon C-2 derivatisation of chitosan has been reported in the case of chitosan carrying oligosaccharide branches (Tømmeraas et al. 2002).

The degree of substitution (DS) was determined from the areas of the signal at $\delta 2.81 \mathrm{ppm}$, which corresponds to the resonance of

Table 1

Properties and DS (degree of substitution) of the chitosan derivatives.

\begin{tabular}{|c|c|c|c|c|}
\hline Derivative & $\begin{array}{l}\text { Molar ratio } \\
\mathrm{R} / \mathrm{NH}_{2}\end{array}$ & DS (potentiometry) & DS $\left({ }^{1} \mathrm{H}\right.$ NMR $)$ & $\operatorname{Mv}(\mathrm{kDa})$ \\
\hline $\mathrm{CH}-\mathrm{C}$ & - & $86.1 \%$ & $85.9 \%$ & 32.8 \\
\hline $\mathrm{CH}^{\mathrm{b}}$ & - & $98.5 \%$ & $98.7 \%$ & 24.4 \\
\hline CH-Propyl-10 & 1.2 & $11.2 \%$ & $10.7 \%$ & 30.3 \\
\hline CH-Propyl-15 & 1.5 & $14.3 \%$ & $14.7 \%$ & 11.9 \\
\hline CH-Propyl-20 & 2.3 & $23.4 \%$ & $18.1 \%$ & 18.8 \\
\hline CH-Propyl-40 & 3.8 & $39.1 \%$ & $38.4 \%$ & - \\
\hline CH-Pentyl-25 & 1.5 & - & $25.1 \%$ & 17.4 \\
\hline CH-Pentyl-30 & 2.5 & - & $30.0 \%$ & - \\
\hline CH-Pentyl-65 & 8.0 & - & $64.9 \%$ & 20.1 \\
\hline
\end{tabular}

a Molar ratio of alkyltrimethylammonium bromide $(\mathrm{R})$ to amino groups $\left(-\mathrm{NH}_{2}\right)$ used in the substitution reaction.

b Deacetylated chitosan. 

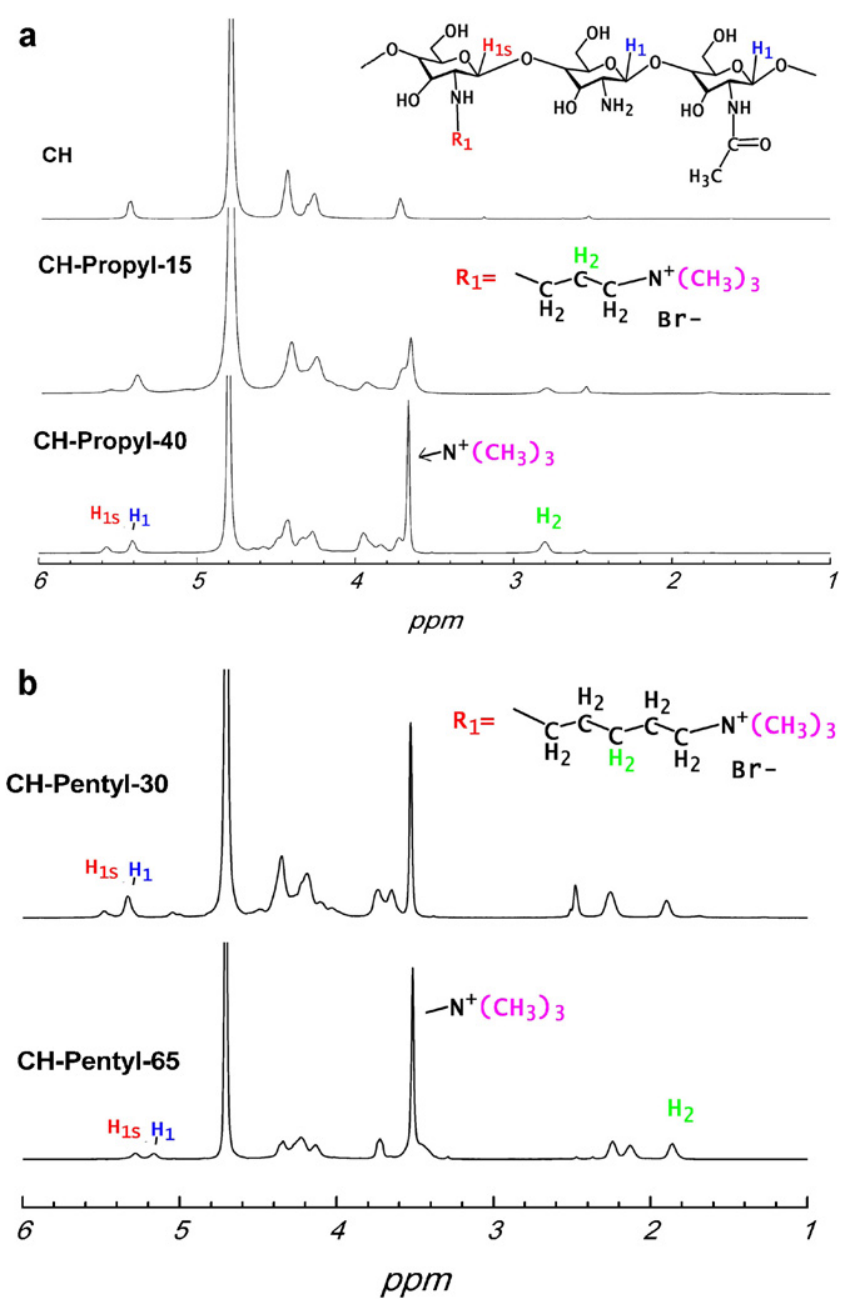

Fig. 2. ${ }^{1} \mathrm{H}$ NMR spectra of deacetylated chitosan and their (a) propyltrimethylammonium and (b) pentyltrimethylammonium derivatives of chitosan. The resonance of the methylene protons (green color) equidistant from the nitrogen atoms was used to determine DS. (For interpretation of the references to color in this figure legend, the reader is referred to the web version of the article.)

the methylene protons $\mathrm{CH}_{2} \mathrm{CH}_{2} \mathrm{CH}_{2} \mathrm{~N}^{+}\left(\mathrm{CH}_{3}\right)_{3}$ (Fig. 2a) and from the signals due to the anomeric protons of propyltrimethylammonium substituted and unsubstituted glucosamine residues, $\mathrm{H}_{1 \mathrm{~s}}$ and $\mathrm{H}_{1}$, respectively (Fig. 2a) using Eq. (1):

$\mathrm{DS}=\frac{(1 / 2) I_{\mathrm{CH}_{2}}}{I_{\mathrm{H}_{1}}+I_{\mathrm{H}_{1 \mathrm{~s}}}}$

The same equation was used to determine DS for the derivatives obtained with pentyltrimethylammonium, however the signal at $\delta$ $2.05 \mathrm{ppm}$, which corresponds to the resonance of the methylene protons $\mathrm{CH}_{2} \mathrm{CH}_{2} \mathrm{CH}_{2} \mathrm{CH}_{2} \mathrm{CH}_{2} \mathrm{~N}^{+}\left(\mathrm{CH}_{3}\right)_{3}$, was utilized for this purpose (Fig. 2b). All degrees of substitution (DS) are shown in Table 1.

\subsection{Antifungal activity of commercial chitosan and its deacetylated and quaternary derivatives}

The antifungal activity against $A$. flavus was previously tested for commercial $(\mathrm{CH}-\mathrm{C})$ and deacetylated $(\mathrm{CH})$ chitosans (Table 1). The concentration range was varied from 0.1 to $1.0 \mathrm{~g} / \mathrm{L}$ and inhibition percentages were calculated as described in the previous section (Section 2.6). The inhibition decreases with time, which is due to the adaptation of the fungus to its new environment, for instance the inhibition index obtained with deacetylated chitosan is 8.1, 6.5 and 5.1 in the 3rd, 5th and 7th day respectively

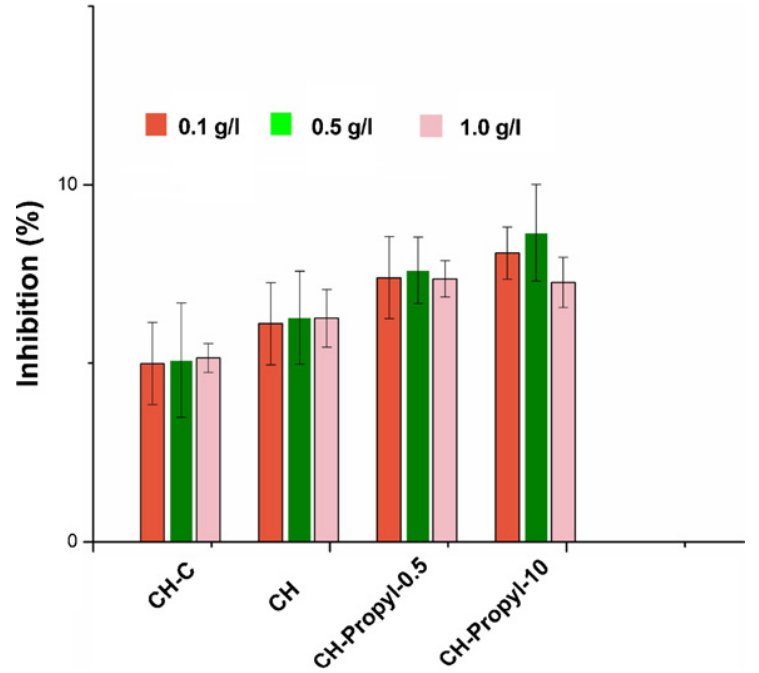

Fig. 3. Inhibition percentages for $\mathrm{CH}-\mathrm{C}$ and $\mathrm{CH}$ at different polymer concentrations. The differences between the groups were not statistically significant with $P<0.05$.

and the same pattern was observed for the other derivatives. As can be seen from Fig. 3 the inhibition percentage obtained for $\mathrm{CH}$ $\mathrm{C}$ and $\mathrm{CH}$ remained around 5\% and increased slightly from 0.1 to $1.0 \mathrm{~g} / \mathrm{L}$ for the derivative substituted with $10 \%$ of propyltrimethyl ammonium groups (CH-Propyl-10), which is due to the low the degree of substitution. This result is similar to that observed by $\mathrm{Li}$ et al. investigating the antifungal activities of chitosans on $F$. fulva. These authors showed that inhibition percentages of low molecular weight chitosans, measured by the mycelial radial growth, exhibited modest increases in the concentration range from 0.1 to $1.0 \mathrm{~g} / \mathrm{L}$ ( Li et al. 2011). Although unexpected, in this work the fungal adaptation to the new environment was rapid and as the time of incubation was 7 days the effect of concentration was not clearly observed. However, the determination of the minimum inhibitory concentrations (MICs), discussed ahead in the paper, makes clear that derivatives having the higher degrees of substitution exhibit a significant inhibition increase.

Although increasing concentrations of chitosan may improve the inhibition percentage on many pathogens this trend depends on several factors such as molecular weight of chitosan, targeted pathogen and pH (Yang et al. 2005). The activity of chitosan has been explained as being based on the electrostatic interaction of the charged amino groups of chitosan with negatively charged cell wall surface of the targeted microorganisms, which can lead to the disruption of the cell wall and therefore to the death of the cell. Another possibility for antifungal activity of chitosan accounts for its chains to cross the cell membrane inhibiting the cell growing from inside (Guo et al. 2007). However, for deacetylated chitosan $(\mathrm{CH})$ and the derivatives having low degrees of substitution the mechanism on A. flavus and the interaction with cell surface may form an impermeable layer around the cell, thus blocking the transport of essential solutes into the cell (Eaton et al. 2008).

In this work, we hypothesized that, the modification of chitosan by introducing permanently charged quaternary groups could improve the antifungal activity of chitosan. The addition of quaternized chitosan to the BDA medium inhibited mycelial growth of A. flavus significantly at all concentrations tested. A representative experiment comparing the effect of $\mathrm{CH}$ and $\mathrm{CH}$-Propyl-40 is shown in Fig. 4. As shown in Fig. 5 the results obtained in microbiological assays showed that the capability to inhibit fungus growth in vitro was clearly increased for the higher degrees of substitution DS for the two series tested ( $\mathrm{CH}$-Propyl and $\mathrm{CH}$-Pentyl). The Student $t$-test was applied to independent samples to a level of 


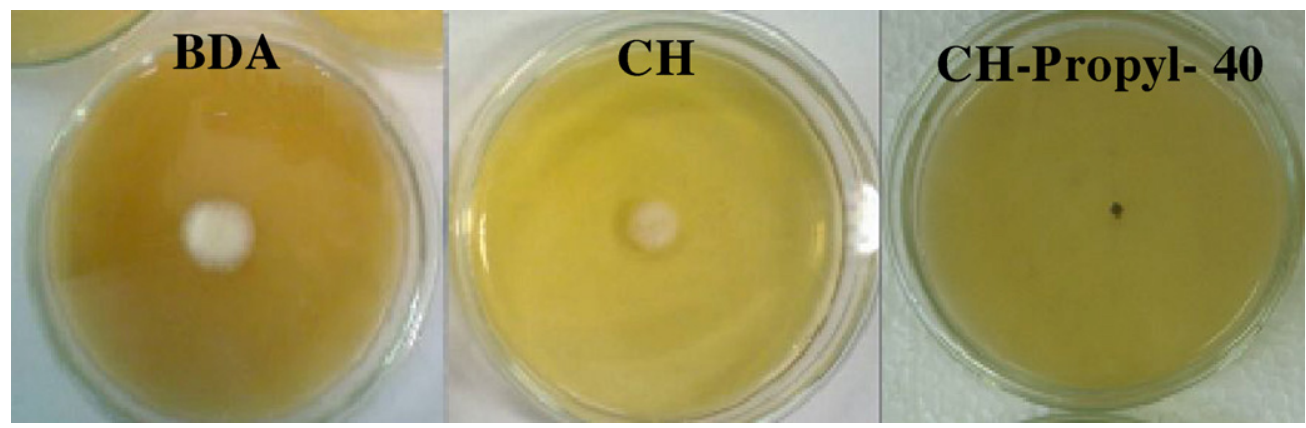

Fig. 4. Comparative effect of the quaternization of chitosan on the inhibition index at $0.5 \mathrm{~g} / \mathrm{L}$ after 3 days of incubation: from left to right BDA; $\mathrm{CH}$ and $\mathrm{CH}-\mathrm{Propyl}-40$.

significance of 0.05 aiming to verify the existence of significant differences between results obtained for the inhibition index with 0.1 and $0.5 \mathrm{~g} / \mathrm{L}$. The descriptive statistics showed that no significant differences were observed regarding the 0.1 and $0.5 \mathrm{~g} / \mathrm{L}$, since the obtained $P$ values were always higher than 0.5 , which confirm that, in this concentration range, the inhibition does not change. A comparison between the inhibition indexes of the different chitosan derivatives was also performed. The Kruskal-Wallis test with Dunn's multiple comparison was utilized to the level of significance 0.05 and the descriptive statistics showed that $P$ values found for $0.1 \mathrm{~g} / \mathrm{L}$ were smaller than 0.001 , indicating that structural changes on the chitosan chain significantly increases the antifungal activity.

The most substituted derivative from CH-Propyl series (DS $=38.5 \%$ ) showed an inhibition index three times higher than that observed with deaceylated chitosan $(\mathrm{CH})$.

However, the highest inhibition index was obtained for $\mathrm{CH}-$ Pentyl derivative having with DS 65\%, which exhibited an inhibition index almost six times higher than $\mathrm{CH}$. As shown by other authors, this activity can be attributed to a higher number of cationic groups available on the polymer chain, which allows a stronger interaction between the polycation chains and the cell wall, increasing the antifungal activity. However by comparing the efficiencies of both series it becomes clear that the less substituted $\mathrm{CH}$ Pentyl derivative ( $D S=25 \%$ ) exhibited a higher inhibition than that obtained using the more substituted derivative from CH-Propyl series (DS $=38.5 \%$ ). Since both the series present the same quaternary group, this higher activity for $\mathrm{CH}$-Pentyl series may be attributed to the longer hydrocarbon chain of the grafted pentyl groups, which could favor a hydrophobic and stronger interaction with the cell membrane.

\subsection{Minimum inhibitory concentrations}

The results obtained from MICs determination confirmed that the cationic derivatives synthesized exhibit increasing efficiencies with the degree of substitution by the cationic groups, with MICs in the range of $1.0-4.0 \mathrm{~g} / \mathrm{L}$. As can be seen from Table 2 in the first $48 \mathrm{~h}$, the derivatives $\mathrm{CH}-$ Pentyl-30, CH-Propyl-40, CH-Pentyl-25 and CHPentyl-65 inhibited completely the growth of the fungus at $1.0 \mathrm{~g} / \mathrm{L}$, i.e., a concentration four times smaller than those needed for commercial ( $\mathrm{CH}-\mathrm{C})$ and deacetylated chitosan $(\mathrm{CH})$ (Table 2). Moreover, after $72 \mathrm{~h}$ no growth was observed in the presence of CH-Pentyl-65

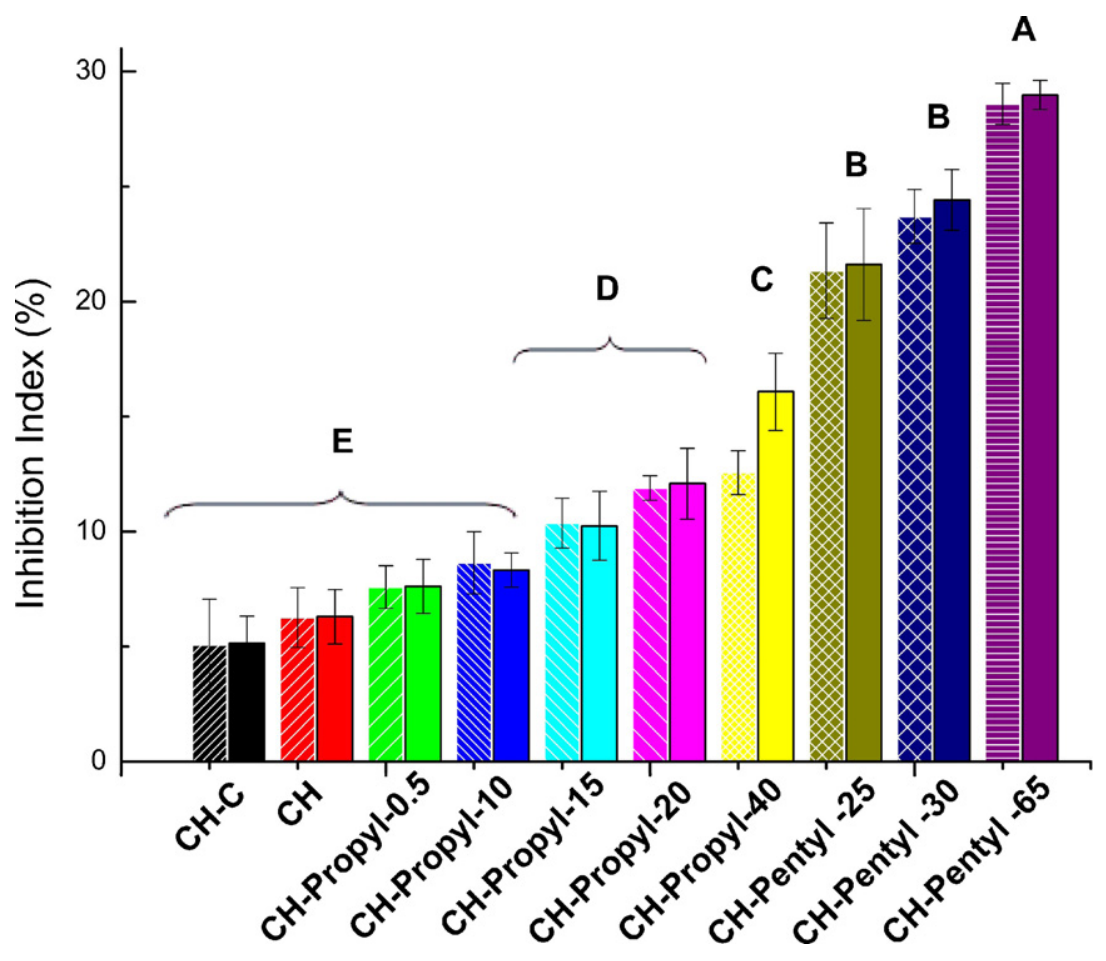

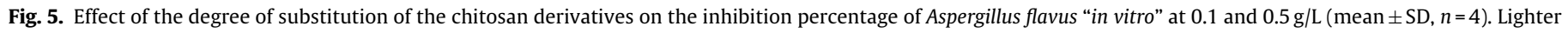

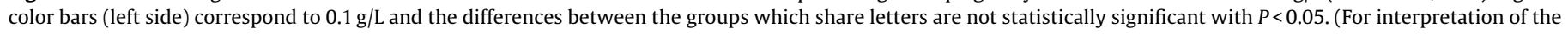
references to color in this figure legend, the reader is referred to the web version of the article.) 
Table 2

Minimum inhibitory concentrations of chitosan and its derivatives.

\begin{tabular}{llll}
\hline & \multicolumn{2}{l}{ MIC $(\mathrm{g} / \mathrm{L})$} & \\
\cline { 2 - 4 } & $24 \mathrm{~h}$ & $48 \mathrm{~h}$ & $\mathrm{~h}$ \\
\hline $\mathrm{CH}-\mathrm{C}$ & 4.0 & 4.0 & 4.0 \\
$\mathrm{CH}$ & 4.0 & 4.0 & 4.0 \\
CH-Propyl-10 & 1.0 & 2.0 & 4.0 \\
CH-Propyl-15 & 0.5 & 2.0 & 4.0 \\
CH-Propyl-20 & 1.0 & 2.0 & 4.0 \\
CH-Propyl-40 & 0.5 & 1.0 & 2.0 \\
CH-Pentyl-25 & 0.5 & 1.0 & 2.0 \\
CH-Pentyl-30 & 0.5 & 1.0 & 2.0 \\
CH-Pentyl-65 & 0.5 & 1.0 & 1.0 \\
\hline
\end{tabular}

at concentration of $2.0 \mathrm{~g} / \mathrm{L}$. The MICs for $\mathrm{CH}-\mathrm{C}$ and $\mathrm{CH}$ was $4.0 \mathrm{~g} / \mathrm{L}$ and this value is within of the range reported in the literature, which varies from 10 to $5000 \mathrm{ppm}$ depending on molecular weight, degree of acetylation and type of fungi (Sajomsang et al. 2012). Similar responses were observed by other authors and the MICs of quaternized chitosans decrease with degree of substitution, which can be explained based on the interaction of these groups with negatively charged cell surface membrane, preventing nutrients from entering the cell (Guo et al. 2007; Yang et al. 2005).

\section{Conclusions}

The synthesis and characterization of new quaternary derivatives of chitosan were carried out and their antifungal activities against $A$. flavus were tested. The results have shown that the antifungal activity of chitosan can be improved by increasing the degree of substitution (DS) of alkyltrimethylammonium groups on the polymer chain. The inhibition indexes for both synthesized series (propyl and pentyltrimethylammonium) increased with DS and the most substituted derivatives (CH-Propyl-40 and CH-Pentyl-65) exhibited inhibition values three and six times respectively higher than those obtained with chitosan. The higher activity exhibited by $\mathrm{CH}-$ Pentyl derivatives can be attributed to the longer hydrocarbon chain of this substituent, which allows a stronger interaction with the cell membrane. The synthesis and characterization of new derivatives, having longer hydrocarbon chains, are ongoing in our laboratory aiming to obtain derivatives with higher antifungal activities.

\section{Acknowledgements}

Financial support by FAPESP (Grant No. 2012/03619-9), FUNDUNESP (Grant 430/09). R.O.P and M.T. thank FAPESP and PET-CAPES for undergraduate fellowship.

\section{References}

Alburquenque C, Bucarey SA, Neira-Carrillo A, Urzúa B, Hermosilla G, Tapia CV. Antifungal activity of low molecular weight chitosan against clinical isolates of Candida spp. Med Mycol 2010;48(8):1018-23.

Binder EM, Tan LM, Chin LJ, Handl J, Richard J. Worldwide occurrence of mycotoxins in commodities, feeds and feed ingredients. Anim Feed Sci Technol $2007 ; 137(3-4): 265-82$
Clinical and Laboratory Standards Institute (CLSI). Reference method for broth dilution antifungal susceptibility testing of filamentous fungi. Approved standard second edition. CLSI document M38-A2 (ISBN 1-56238-668-9); 2008.

Domard A. A perspective on 30 years research on chitin and chitosan. Carbohydr Polym 2011;84(2):696-703.

Eaton P, Fernandes JC, Pereira E, Pintado ME, Malcata FX. Atomic force microscopy study of the antibacterial effects of chitosans on Escherichia coli and Staphylococcus aureus. Ultramicroscopy 2008;108(10):1128-34.

El Ghaouth A, Arul J, Asselin A, Benhamou N. Antifungal activity of chitosan on postharvest pathogens: induction of morphological and cytological alterations in Rhizopus stolonifer. Mycol Res 1992;96(9):769-79.

Fajardo JE, Waniska RD, Cuero RG, Pettit RE. Phenolic-compounds in peanut seeds - enhanced elicitation by chitosan and effects on growth and aflatoxin B-1 production by Aspergillus flavus. Food Biotechnol 1994;8(2-3):191-211.

Guo ZY, Chen R, Xing R, Liu S, Yu H, Wang P, et al. Novel derivatives of chitosan and their antifungal activities in vitro. Carbohydr Res 2006;341(3):351-4.

Guo ZY, Xing R, Liu S, Zhong Z, Ji X, Wang L, et al. The influence of the cationic of quaternized chitosan on antifungal activity. Int J Food Microbiol 2007:118(2):214-7.

Jayakumar R, Prabaharan M, Sudheesh Kumar PT, Nair SV, Tamura H. Biomaterials based on chitin and chitosan in wound dressing applications. Biotechnol Adv 2011;29(3):322-37.

Jayakumar R, Prabaharan M, Nair SV, Tokura S, Tamura H, Selvamurugan N. Novel carboxymethyl derivatives of chitin and chitosan materials and their biomedical applications. Prog Mater Sci 2010;55(7):675-709.

Kean T, Thanou M. Biodegradation, biodistribution and toxicity of chitosan. Adv Drug Deliver Rev 2010;62(1):3-11.

Kenawy El-R, Abdel-Hay FI, El-Magd AA, Mahmoud Y. Biologically active polymers: modification and anti-microbial activity of chitosan derivatives. J Bioact Compat Polym 2005;20:95-111.

Li MQ, Chen XG, Liu JM, Zhang WF, Tang XX. Molecular weight-dependent antifungal activity and action mode of chitosan against Fulvia fulva (Cooke) Ciffrri. J Appl Polym Sci 2011;119(6):3127-35.

Másson M, Holappa J, Hjálmarsdóttir M, Rúnarsson ÖV, Nevalainen T, Järvinen T. Antimicrobial activity of piperazine derivatives of chitosan. Carbohydr Polym 2008;74(3):566-71.

Muzzarelli RAA, Muzzarelli C, Tarsi R, Miliani M, Gabbanelli F, Cartolari M. Fungistatic activity of modified chitosans against Saprolegnia parasitica. Biomacromolecules 2001;2(1):165-9.

Ngah WSW, Teong LC. Hanafiah MAKM adsorption of dyes and heavy metal ions by chitosan composites: a review. Carbohydr Polym 2011;83(4):1446-56.

Ravi Kumar MNV. A review of chitin and chitosan applications. React Funct Polym 2000;46(1):1-27.

Roberts GAF, Wang W. Evaluation of Mark-Houwink viscosimetric constants for chitosan. In: Domard J, Muzzarelli R, editors. Advances in chitin science. Lyon: Jacques Andre; 1996. p. 279-84.

Rinaudo M. Chitin and chitosan: properties and applications. Prog Polym Sci 2006;31(7):603-32.

Sajomsang W, Gonil P, Saesoo S, Ovatlarnporn C. Antifungal property of quaternized chitosan and its derivatives. Int J Biol Macromol 2012;50(1):263-9.

Satpathy G, Tyagi YK, Gupta RK. A novel optimised and validated method for analysis of multi-residues of pesticides in fruits and vegetables by microwaveassisted extraction (MAE)-dispersive solid-phase extraction (d-SPE)-retention time locked (RTL)-gas chromatography-mass spectrometry with deconvolution reporting software (DRS). Food Chem 2011;127(3):1300-8.

Shahidi F, Arachchi JKV, Jeon YJ. Food applications of chitin and chitosans. Trends Food Sci Technol 1999;10(2):37-51.

Shi CM, Zhu Y, Ran X, Wang M, Su Y, Cheng T. Therapeutic potential of chitosan and its derivatives in regenerative medicine. J Surg Res 2006;133(2):185-92.

Tiera MJ, Qiu XP, Bechaouch S, Shi Q, Fernandes JC, Winnik FM. Synthesis and characterization of phosphorylcholine-substituted chitosans soluble in physiological pH conditions. Biomacromolecules 2006;7(11):3151-6.

Tømmeraas K, Köping-Höggård $M$, Vårum KM, Christensen BE, Artursson $\mathrm{P}$, Smidsrød O. Preparation and characterisation of chitosans with oligosaccharide branches. Carbohydr Res 2002;337(24):2455-62.

Xu T, Xin M, Li M, Huang H, Zhou S, Liu J. Synthesis, characterization, and antibacterial activity of N,O-quaternary ammonium chitosan. Carbohydr Res 2011:346(15):2445-50.

Yang TC, Chou CC, Li CF. Antibacterial activity of N-alkylated disaccharide chitosan derivatives. Int J Food Microbiol 2005;97(3):237-45.

Zhang B, Wang DF, Li HY, Xu Y, Zhang L. Preparation and properties of chitosan-soybean trypsin inhibitor blend film with anti-Aspergillus flavus activity. Ind Crop Prod 2009;29(2-3):541-8.

Zhang HY, Li RP, Liu WM. Effects of chitin and its derivative chitosan on postharvest decay of fruits: a review. Int J Mol Sci 2011;12(2):917-34. 